\title{
Improving Student Learning Performance during On-line Lectures
}

\author{
Sangle Santosh ${ }^{1}$, Joshi Ajinkya ${ }^{2}$, Pawar Padmakar ${ }^{3}$, Nandurkar Keshav ${ }^{4}$ \\ ${ }^{1}$ Assistant Professor, Production Engineering, K. K. Wagh Institute of Engineering Education and Research, Nashik \\ ${ }^{2}$ Associate Professor and I/C Registrar, K. K. Wagh Institute of Engineering Education and Research, Nashik \\ ${ }^{3}$ Professor and Head, Production Engineering, K. K. Wagh Institute of Engineering Education and Research, Nashik \\ ${ }^{4}$ Principal, K. K. Wagh Institute of Engineering Education and Research, Nashik \\ ${ }^{1}$ santoshbsangle@yahoo.in, ${ }^{2}$ ajinkya_j@ rediffmail.com, ${ }^{3}$ pjpawar1@rediffmail.com, ${ }^{4}$ keshav1965@gmail.com
}

\begin{abstract}
The comparison of pre and post Covid-19 performance is now being made in many areas. The invisible enemy in the form of Covid-19 virus has put a sturdy impact on many sectors and has forced these sectors to change their mode of operation. Education sector is the most affected sector due to this pandemic. Teachers have adapted to the online teaching methodology through various e-platforms. Feedback collected from the teachers suggested that most of the teachers are facing the problem of engaging the students effectively during the online lectures. Also it is challenging to ensure that students have acquired all knowledge levels as per Bloom's Taxonomy during online learning.
\end{abstract}

A study was undertaken wherein 200 students were randomly divided into four equal groups. Online lectures on the same topic by the same instructor were arranged for every group. A different methodology of content delivery namely a) explanation by display of textual information, b) use of pictures, c) use of video content and d) use of numerical examples based on different learning styles reported in the literature. At the end of the lectures, students were assigned six questions corresponding to each level of the Bloom's Taxonomy.

The student responses were mapped and analyzed. The ranking of groups has been calculated using Technique for Order of Preference by Similarity to Ideal Solution (TOPSIS). It shows that group number four where text, picture at low level and video, numerical at high level has first rank with score of 0.350 . The Pearson correlation between the groups was also determined. The correlation indicates that there is a positive correlation between group two and group four that means a combination of pictures, video and numerical at high level may leads to better results.

This result can be useful for teachers to finding the most effective proportion of content type to map various levels of Bloom's Taxonomy and thereby improve the learning performance of students during online teaching.
Keywords: Covid-19; Online teaching; Bloom's Taxonomy; Student engagement; TOPSIS; Correlation matrix; Learning performance.

\section{Introduction}

Education facilitates learning and acquisition of skills, knowledge, beliefs, values, attitudes and habits. It is an inseparable part of human life. Education enlightens the lives of individuals and plays an important role in the development of the country (Johan and Harlan, 2014). Online teaching - learning is the process where education takes place over the internet (Sadiku et. al., 2018). Following the outbreak of Covid-19 pandemic, many developing countries have started adapting online teaching and learning methods through various e-platforms due to lockdown declared by most of the countries.

Online courses are those courses where at least $80 \%$ of the content is delivered in an online manner while offline courses refer to those courses where entire content delivery occurs by face-to-face traditional method (Alsaaty et. al., 2016). There are several challenges faced by the teachers during online content delivery. Some of these include infrastructural requirements and availability of technology especially in developing countries, capability in handling various ICT tools effectively, language barrier (Singh, 2016) and most importantly engagement of the students during the online sessions. Although students prefer online education, they too often face barriers particularly while participating in the group activities and personal commitments such as caring and employment responsibilities (Gillett-Swan, 2017).

Bloom's Taxonomy is a classification system for different levels of cognitive skills and learning behaviour. It classifies thinking into six levels in the increasing order of complexity and provides a framework to focus on higher order thinking (Vijaykumar et. al., 2016). These levels are remembering, understanding, applying, analyzing, evaluating and creating. First three levels are classified as low order learning skills while the next three levels as critical level or higher order skills (Chug and Madhuravani, 2016). Bloom's Taxonomy functions as a catalyst to improvise the participation of students in 
the classroom and thereby helps to enhance the teachinglearning process (Brindha, 2020). The revised Bloom's Taxonomy is shown in figure 1.

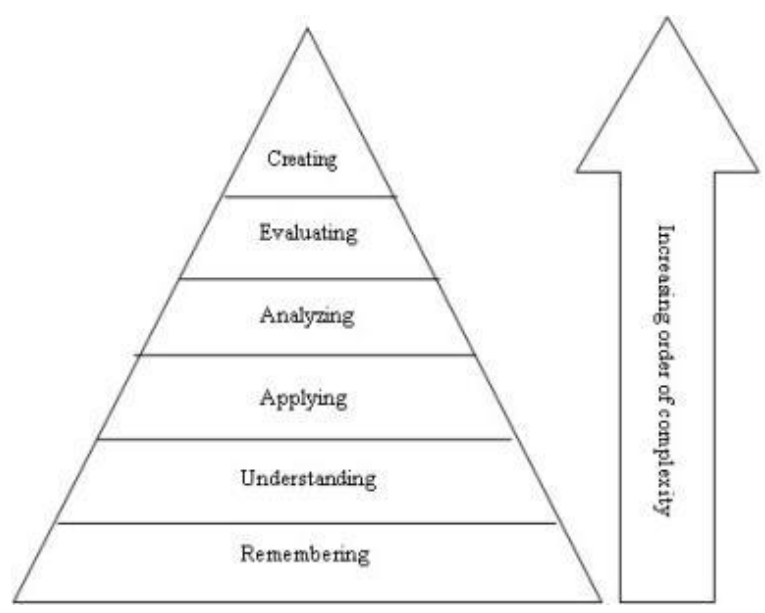

Fig. 1: Bloom's Taxonomy

In the case of face-to-face methods of content delivery, the mapping is readily available and gaps are mostly identified. Felder and Silverman (1988) have discussed the different learning and teaching styles relevant to engineering education. Different methodologies can be adopted for delivery of content during the online sessions. These include providing explanation through display of textual information, conveying the information by using pictures, using audio-video content and explaining the subject through numerical examples. Further the actual video of the teacher may or may not be made available to the students during the online lectures. This study has made use of the actual video of the teacher for all experimental groups.

In the present study, the entire student population for the course was divided into four equal groups on a random basis. The same teacher taught the same concepts to these groups for the same duration but using four different methods mentioned above. Online assessment of the students was carried out at the end of all lectures by assigning multiple choice questions that addressed all six levels of the Bloom's Taxonomy.

The purpose of this study is to determine the most effective mode of content delivery or a combination of different modes of content delivery to address a particular level of Bloom's Taxonomy. The outcome of the study will be useful for effective student engagement as well as for enhancing the quality of online teachinglearning process. The study will also reveal how different modes of content delivery are co-related with each other.

\section{Literature review}

Paul and Jefferson (2019) conducted a study to determine the effectiveness of on-line and traditional instructional methods over an eight-year period. Final course grades of 548 participants were used to assess the performance between online and face-to-face instructional methods. The entire course was taught to both the groups by a senior faculty and the same content was delivered during each lecture. Chi-square test and Anova were used to analyze the data. Results indicated that there was no significant difference in the performance of online and traditional instructional methods. Authors have however opined that the institutions of higher education may shift from the traditional instructional method to online method so that it can lead to a larger buyer population, cost efficiency and more revenue.

A study was undertaken to determine the impact of on-line resources on student-teacher relationships (Alshahrani et. al., 2017). The data were collected from 1942 undergraduate students from the United Kingdom, Saudi Arabia and Kenya by employing online and paper based questionnaires. Simple statistical approach was adopted to analyze quantitative data while qualitative data was analysed by thematic analysis approach. Results indicate that the use of the internet has improved the academic self-confidence and self-reliance of the students. This has however created a gap in the studentteacher and referent relationship.

Elfaki et. al. (2019) conducted a study in Najran University to assess the impact of e-learning on the performance and attitude of the students. Eighty students were divided into two equal groups. E-learning style was adopted for the first group while traditional learning style was adopted for the other. The objectives, contents, assignments and assessments were the same for both groups. Final exam results and questionnaires were used to collect the data. The data were analyzed using the SPSS statistical software. Results indicate that mean scores of students from the e-learning group were significantly higher than those obtained by the traditional group. The overall satisfaction and attitude of students from the e-learning group was also higher than that of the traditional group.

A study was conducted to examine student progress in traditional teaching as compared to online mode for the same course (Hurlbut, 2018). One section of the course was taught online while the other in a traditional face-toface format by the same instructor with approximately the same number of enrollment for both courses. Responses were obtained by using questionnaires with open ended questions and Likert scale. Quantitative analysis was obtained through use of SPSS while qualitative data were analyzed using NVIVO 11. Results of the study indicate that students were satisfied with both formats. Students 
enrolled in traditional courses did not display any significant advantage over students enrolled in online courses. At the same time, students who were comfortable with the online teaching mode performed better than their counterparts.

A study was undertaken at Wichita State University to compare student satisfaction and learning outcomes in an undergraduate pharmacology course using online and traditional modes (Mirakian and Hale, 2007). Teaching for both modes was carried out by the same instructor and using the same study material, learning objectives and grading scale. The data of 224 students enrolled for the course was analyzed by using SPSS 13.0. It was observed that although students enrolled in online courses were highly satisfied with the course and their self-perceived knowledge gains, the satisfaction ratings were lower than those of the traditional courses.

Most of the published research has focused on the effectiveness of online teaching and problems faced by the teachers and students. On the other hand, this study aims to determine how the different modes that can be adopted for online teaching will map with a particular level of the Bloom's Taxonomy. Such an understanding will lead to selection of appropriate online mode(s) or a combination of modes for the attainment of objectives.

\section{Methodology}

In the study, 212 students of Mechanical and Production undergraduate engineering courses were randomly divided into four equal groups. Out of these students 200 students actually attended the online lectures. The topic casting and pattern allowances has been selected for the online lecture. The characteristics of respondents are shown in table 1 .

Table 1. Characteristics of respondents

\begin{tabular}{lc}
\hline \multicolumn{1}{c}{ Respondent characteristics } & Value \\
\hline $\begin{array}{l}\text { Total number of students attending } \\
\text { online modes }\end{array}$ & 200 \\
Sex ratio (Male : Female) & $58: 42$ \\
Age group & 20 to 22 years \\
\hline
\end{tabular}

The male: female ratio for every online class was approximately the same. A topic "Casting and Shrinkage Allowance" common for both branches was selected for online teaching. The same instructor conducted the online lectures for all groups and the same content was delivered to all groups. By changing the proportion of presentation content form such as textual, pictorial, use of video and use of numerical content, one online lecture was delivered to each group using the GoToMeeting platform. The combination of online modes used for every group is shown in table 2. In this table $\mathrm{H}$ represent high and $\mathrm{L}$ represent low.

Table 2: Combination of online modes for content delivery to different groups

\begin{tabular}{ccccc}
\hline Group No. & Text & Picture & Video & Numerical \\
\hline 1 & H & H & L & L \\
\hline 2 & L & H & L & H \\
\hline 3 & H & L & H & L \\
\hline 4 & L & L & H & H \\
\hline
\end{tabular}

Multiple choice questions were set to map each level of Bloom's taxonomy such as Remembering, Understanding, Applying, Analyzing, Evaluating and Creating. Assessment is a complex activity and necessitates efforts on the part of both teachers and students (Sangle et. al., 2020). Google Forms provide a convenient way of collecting information from the respondents. Use of Google Forms also enables quick responses and transparency in the data collection process (Shahabadkar et. al., 2019). Multiple choice questions were posed to the students through the Google Forms. Students were allocated 15 minutes for submitting their responses. The same set of multiple choice questions were posed to the four groups and responses of the student were recorded and analyzed. The process flow for the activity has been shown in figure 2 .

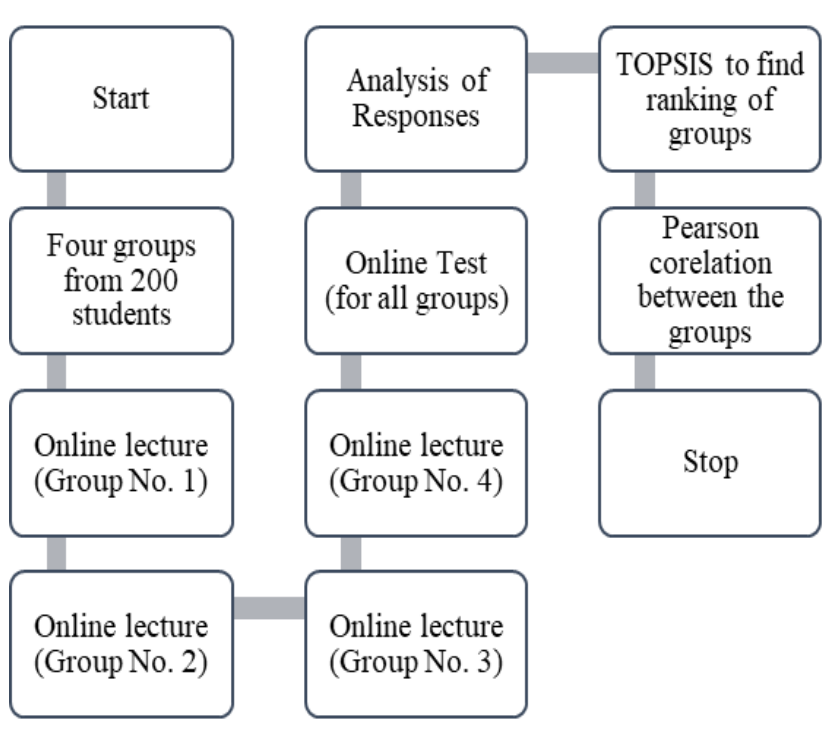

Fig. 2: Process flow for online lectures and assessment

Group 1: The presentation for the online lecture was organized with $40 \%$ textual information, $40 \%$ pictorial, 
$10 \%$ video content and $10 \%$ numerical. This means that out of every ten slides, four slides contained textual information, four slides included pictures, one slide incorporated video and one slide was used for numerical. The time of the lecture was divided in the same proportion. This means that out of 30 minutes, twelve minutes were spent on textual information, twelve minutes on pictorial content, three minutes on video content and three minutes on numerical.

Group 2: The presentation for the online lecture was organized with $40 \%$ pictorial information, $40 \%$ numerical, $10 \%$ video content and $10 \%$ textual information. This means that out of every ten slides, four slides contained pictorial information, four slides included numerical, one slide incorporated video and one slide was used for textual information. The time of the lecture was divided in the same proportion. This means that out of 30 minutes, twelve minutes were spent on pictorial information, twelve minutes on numerical, three minutes on video content and three minutes on textual information.

Group 3: The presentation for the online lecture was organized with $40 \%$ textual information, $40 \%$ video content, $10 \%$ pictorial information and $10 \%$ numerical. This means that out of every ten slides, four slides contained textual information, four slides incorporated video content, one slide included pictures and one slide was used for numerical. The time of the lecture was divided in the same proportion. This means that out of 30 minutes, twelve minutes were spent on textual information, twelve minutes on video content, three minutes on pictorial information and three minutes on numerical.

Group 4: The presentation for the online lecture was organized with $40 \%$ video content, $40 \%$ numerical, $10 \%$ textual information and $10 \%$ pictorial information. This means that out of every ten slides, four slides incorporated video content, four slides included numerical, one slide included textual information and one slide was used for pictorial information. The time of the lecture was divided in the same proportion. This means that out of 30 minutes, twelve minutes were spent on video content, twelve minutes on numerical, three minutes on textual information and three minutes on pictorial information.

Questionnaires were provided to each student after all lectures has been completed. Questionnaires were composed of six multiple choice questions with one questions mapping each level of the Bloom's Taxonomy.

Q.1: In the area of manufacturing which of the following definitions describe the casting? (Remembering) a. Molten metal is poured into the pattern and allows it to solidify.

b. Molten metal is poured into the mould cavity and alloy it to solidify

c. Pouring molten metal into a mould and taking it out after it becomes vapour.

d. Process in which product gets by plastic deformation of metal.

Q.2: Select the correct sequence of casting process (Understanding)

a. Pouring, Pattern making, Mould preparation, Fettling.

b. Fettling, Pattern making, mould preparation, pouring.

c. Mould preparation, Pattern making, mould preparation, pouring, Fettling.

d. Pattern making, mould preparation, pouring, Fettling

Q.3: Which one of the following materials will require the largest size of riser for the same size of casting? (Applying)
a. Aluminium
b. Cast iron
c. Steel
d. Copper

Q.4: Assertion (A): A pattern is a replica of the casting it means that pattern made exactly similar to the part to be cast. Reasoning (R): Pattern is used to make the mould cavity for pouring in molten for casting. (Analyzing)

a. Both $\mathrm{A}$ and $\mathrm{R}$ are individually true and $\mathrm{R}$ is the correct explanation of $\mathrm{A}$.

b. Both $\mathrm{A}$ and $\mathrm{R}$ are individually true but $\mathrm{R}$ is not the correct explanation of $\mathrm{A}$.

c. A is true but $\mathrm{R}$ is false.

d. A is false but $\mathrm{R}$ is true.

Q.5: In grey cast iron and spheroidal graphite iron, the amount of graphitization controls the actual shrinkage. When graphitization is more, the shrinkage would be less and vice versa. If graphitization is much more that grey cast iron and spheroidal graphite iron start expanding. In this case: (Evaluating)

a. Pattern size is less than casting

b. Pattern size is more than casting.

c. Pattern size is the same as casting.

d. None of the above.

Q.6: A cubic casting of $50 \mathrm{~mm}$ side undergoes volumetric solidification shrinkage and volumetric solid contraction of $4 \%$ and $6 \%$ respectively. No riser is used. Assume uniform cooling in all directions. The side of the cube after solidification and contraction is: (Creating)
a. $48.32 \mathrm{~mm}$
b. $49.90 \mathrm{~mm}$
c. $49.94 \mathrm{~mm}$ 


\section{d. $49.96 \mathrm{~mm}$}

The percentage of correct responses for every group is shown in table 3 .

Table 3: Number of students who gave correct responses for every online mode with the corresponding level of Bloom's Taxonomy

\begin{tabular}{|c|c|c|c|c|}
\hline \multirow{2}{*}{$\begin{array}{l}\text { Level of } \\
\text { Bloom's } \\
\text { Taxonomy } \\
\text { addressed }\end{array}$} & \multicolumn{4}{|c|}{$\begin{array}{l}\text { Number of students give correc } \\
\text { responses after conducting online lecture }\end{array}$} \\
\hline & $\begin{array}{l}\text { Group } \\
\text { No. } 1\end{array}$ & $\begin{array}{l}\text { Group } \\
\text { No. } 2\end{array}$ & $\begin{array}{l}\text { Group } \\
\text { No. } 3\end{array}$ & $\begin{array}{l}\text { Group } \\
\text { No. } 4\end{array}$ \\
\hline Level 1 & 38 & 46 & 50 & 18 \\
\hline Level 2 & 50 & 42 & 34 & 40 \\
\hline Level 3 & 40 & 26 & 44 & 20 \\
\hline Level 4 & 35 & 40 & 21 & 49 \\
\hline Level 5 & 38 & 46 & 50 & 18 \\
\hline Level 6 & 50 & 42 & 34 & 40 \\
\hline
\end{tabular}

The responses collected from students were used to rank the groups by employing a well-known MCDM method - Technique for Order of Preference by Similarity to Ideal Solution (TOPSIS). Correlation between groups was also determined using Pearson correlation. These are discussed in the following subsections:

\subsection{Application of TOPSIS methodology:}

The TOPSIS method, originally developed by Hwang and Yoon (1981), was developed further by Yoon (1987) and Hwang et al. (1993). In this method, the chosen alternative has the shortest geometric distance from the positive ideal solution (PIS) and farthest geometric distance from the negative ideal solution (NIS). The PIS maximizes the benefit criteria and minimizes the cost while the NIS increases the cost criteria and reduces the benefit criteria (Rao, 2007; Joshi et. al., 2017). Steps involved in TOPSIS are as follows:

\section{Step 1: Identifying evaluation attributes}

Four combinations of online modes for content delivery to different groupswere mapped with the different levels of Bloom's Taxonomy. The responses obtained from the students were converted to a 0-1 scale and tabulated in an electronic spreadsheet. Average values obtained from the spreadsheet were used to prepare the evaluation matrix.

Step 2: Creating evaluation matrix and obtaining a normalized decision matrix
An evaluation (decision) matrix consisting of $\mathrm{m}$ attributes and $\mathrm{n}$ criteria for every group and Blooms Taxonomy level was prepared. The intersection of every attribute and criteria is given as xij. Thereafter normalized decision matrices were prepared using following equation:

$$
R_{i j}=\frac{x_{i j}}{\sqrt{\sum_{j=1}^{M} x_{i j}^{2}}}
$$

where $i=1,2, \ldots . . m$ and $j=1,2, \ldots . n$

Values of normalized decision matrix are shown in table 4.

Table 4: Values normalized decision matrix

\begin{tabular}{ccccccc}
\hline $\begin{array}{c}\text { Group } \\
\text { No }\end{array}$ & $\begin{array}{c}\text { Level } \\
1\end{array}$ & $\begin{array}{c}\text { Level } \\
2\end{array}$ & $\begin{array}{c}\text { Level } \\
3\end{array}$ & $\begin{array}{c}\text { Level } \\
4\end{array}$ & $\begin{array}{c}\text { Level } \\
5\end{array}$ & $\begin{array}{c}\text { Level } \\
6\end{array}$ \\
\hline 1 & 0.462 & 0.586 & 0.644 & 0.262 & 0.403 & 0.271 \\
2 & 0.608 & 0.535 & 0.438 & 0.582 & 0.605 & 0.515 \\
3 & 0.486 & 0.331 & 0.566 & 0.291 & 0.282 & 0.000 \\
4 & 0.425 & 0.510 & 0.270 & 0.713 & 0.625 & 0.813 \\
\hline
\end{tabular}

Step 3: Obtaining of weighted normalized matrix

It was assumed that all attributes are equally important. Hence equal weights (0.167) were assigned to every attribute. Weighted normalized matriceswere obtained by multiplying every normalized decision matrix by the assigned weight. Weighted normalized matrix was calculated using the following equation:

$$
V_{i j}=w_{j} \times R_{i j}
$$

where $\mathrm{i}=1,2, \ldots . \mathrm{m}, \mathrm{j}=1,2, \ldots \mathrm{n}$ and $\mathrm{w} \mathrm{j}$ represents weight of the $\mathrm{j}$ thattribute.

Step 4: Determining positive ideal $(\mathrm{V}+)$ and negative ideal (V-) solution

The values for positive and negative ideal solution were determined using the following equation:

$V^{+}=\left(V_{1}^{+}, V_{2}^{+}, \ldots, V_{n}^{+}\right)$maximum values and

$V^{-}=\left(V_{1}^{-}, V_{2}^{-}, \ldots, V_{n}^{-}\right)$minimum values

The values for positive ideal solution (PIS) and negative ideal solution (NIS) obtained for the six levels of the Bloom's Taxonomy are shown in table 5.

Table 5: Values for Positive and Negative Ideal Solution

\begin{tabular}{ccccccc}
\hline PIS / & \multicolumn{6}{c}{ Bloom's Taxonomy Level } \\
\cline { 2 - 7 } NIS & 1 & 2 & 3 & 4 & 5 & 6 \\
\hline (PIS) & 0.101 & 0.098 & 0.108 & 0.119 & 0.104 & 0.136
\end{tabular}




\begin{tabular}{ccccccc}
\hline $\mathrm{V}+$ & & & & & & \\
$\begin{array}{c}\text { (NIS) } \\
\text { V- }\end{array}$ & 0.071 & 0.055 & 0.045 & 0.044 & 0.047 & 0.000 \\
\hline
\end{tabular}

Step 5: Calculation of separation measures using ndimensional Euclidean distance

Separation of every alternative from the positive and negative ideal solution was carried out using the following equation:

$$
\begin{aligned}
& S_{j}^{+}=\sqrt{\sum_{i=1}^{n}\left(V_{i j}-V_{i}^{+}\right)^{2}} \quad \text { and } \\
& S_{j}^{-}=\sqrt{\sum_{i=1}^{n}\left(V_{i j}-V_{i}^{-}\right)^{2}}
\end{aligned}
$$

where $\mathrm{j}=1,2, ., \mathrm{N}$.

Calculation of separation measures using ndimensional Euclidean distance are shown in table 6.

Table 6: Separation values for every group

\begin{tabular}{lccccc}
\hline \multicolumn{2}{l}{$\begin{array}{l}\text { Separation } \\
\text { value from }\end{array}$} & \multicolumn{4}{c}{ Group No. } \\
\cline { 2 - 6 } & $\mathbf{1}$ & $\mathbf{2}$ & $\mathbf{3}$ & $\mathbf{4}$ \\
\hline PIS & S+ & 0.126 & 0.065 & 0.171 & 0.071 \\
NIS & S- & 0.091 & 0.127 & 0.051 & 0.168 \\
\hline
\end{tabular}

Step 6: Calculation of closeness coefficient (P) and percentage contribution

Using the separation values of PIS and NIS, closeness coefficient was calculated with the help of following equation:

$$
P_{j}=\frac{S_{j}^{-}}{S_{j}^{+}+S_{j}^{-}}
$$

Finally, percentage contribution of every strategy was calculated using following equation:

$$
P C_{j}=\frac{P_{j}}{\sum P_{j}} \times 100
$$

\subsection{Pearson correlation:}

Pearson's correlation coefficient is the covariance of the two variables divided by the product of their standard deviations. It has a value between +1 and -1 . A value of +1 indicates total positive linear correlation, 0 indicates no linear correlation, and -1 indicates total negative linear correlation.

$$
\rho_{X, Y}=\frac{\operatorname{Cov}(X, Y)}{\sigma_{X} \sigma_{Y}}
$$

\section{Results and discussion}

The percentage contribution of every group was calculated using equation no. 6. Accordingly, ranks for the groups were determined. It shows that group four where text, pictures are at low level and video, numerical at high level has been ranked first with score of 0.350 . Thus, combination of content delivery used for group four is more significant in attainment of levels of Bloom's Taxonomy. The ranking of the groups and respective scores is shown the table 7 .

Table 7: Score and ranking of groups

\begin{tabular}{ccc}
\hline Group & Score & Rank \\
\hline G1 & 0.208 & 3 \\
G2 & 0.328 & 2 \\
G3 & 0.114 & 4 \\
G4 & 0.350 & 1 \\
\hline
\end{tabular}

For further improvement of the proposed methodologies for online teaching, Pearson correlation between these methods was evaluated. The correlation indicates that there is a positive correlation between group two and group four. That means a combination of pictures; video and numerical at high level may leads to better results. The negative correlation between the groups shows that the combination of these groups may give adverse result on level attainment. The Pearson correlation matrix between the groups is shown in table 8 .

Table 8: Pearson Correlation between groups

\begin{tabular}{ccccc}
\hline & G1 & G2 & G3 & G4 \\
\hline G1 & 1 & -0.175 & -0.138 & -0.231 \\
G2 & -0.175 & 1 & -0.180 & 0.136 \\
G3 & -0.138 & -0.180 & 1 & -0.106 \\
G4 & -0.231 & 0.136 & -0.106 & 1 \\
\hline
\end{tabular}

\section{Limitations}

The present study was carried out for one particular course and less number of lectures. It may be noted that some courses are theoretical in nature while some courses are purely mathematical. Therefore, results of one course cannot be directly made applicable for all other courses. To obtain fairly accurate results, authors recommend extension of such an exercise for all courses throughout the semester.

\section{Conclusion}


The experimental study with set of four online lectures has been conducted to study the effect of proportion of content type namely text, picture, video and numerical in online teaching on attainment of Bloom's Taxonomy levels. TOPSIS methodology has been used for determining the ranking of groups. The Pearson correlation has been evaluated between the groups for further betterment of results. The important conclusions drawn from the study are summarized below:

TOPSIS result shows that group number four where text, pictures are at low level and video, numerical at high level has first rank with score of 0.350 . Thus, combination of content delivery used for group four is more significant in attainment of levels of Bloom's Taxonomy.

The correlation between the groups indicates that there is a positive correlation between group two and group four. That means a combination of pictures; video and numerical at high level may lead to better results.

Teachers can use the result as a guideline to select the most effective method for mapping various levels of Bloom's Taxonomy and thereby improve the learning performance of students during online teaching.

\section{References}

Alsaaty, F. M., Carter, E., Abrahams, D. and Alshameri, F. (2016), Traditional Versus Online Learning in Institutions of Higher Education: Minority Business Students' Perceptions, Business and Management Research, 5(2), pp. 31-41.

Alshahrani, S., Ahmed, E. and Ward, R. (2017), The influence of online resources on student-lecturer relationship in higher education: a comparison study, Journal of Computers in Education, 4(2), pp. 87-106.

Brindha, V. E. (2020), Outcome Based Education and Revised Bloom's Taxonomy as a Catalyst for Redesigning Teaching and Learning in Engineering Education, Journal of Engineering Education Transformations, 34(1), pp. 109-114.

Chug, K. L. and Madhuravani, B. (2016), On-Line Engineering Education with Emphasis on Application of Bloom's Taxonomy, Journal of Engineering Education Transformations, Special Issue 2016, DOI: 10.16920/jeet/2016/v0i0/85709

Elfaki, N. K., Abdulraheem, I. and Abdulrahim, R. (2019), Impact of E-Learning vs Traditional Learning on Student's Performance and Attitude, International Journal of Medical Research \& Health Sciences, 8(10), pp. 76-82.

Felder, R. M. and Silverman, L. K. (1988), Learning and Teaching styles in Engineering Education, Engineering. Education, 78(7), pp. 674-681.

Gillett-Swan, J. (2017), The Challenges of Online Learning Supporting and Engaging the Isolated Learner, Journal of Learning Design, 10(1), pp. 20-30.
Hurlbut, A. R. (2018), Online vs. traditional learning in teacher education: a comparison of student progress, American Journal of Distance Education, 32(4), pp. 248266.

Hwang, C. L. and Yoon, K. (1981), Multiple Attribute Decision Making: Methods and Applications: a state-ofthe-art survey, Springer-Verlag, New York.

Hwang, C. L., Lai, Y. J. and Liu, T. Y. (1993), A New Approach for Multiple Objective Decision Making, Computers and Operational Research, 20(8), pp. 889-899.

Johan, R. and Harlan, J. (2014), Education Nowadays, International Journal of Educational Science and Research, 4(5), pp. 51-56.

Joshi, A. S., Deshpande, V. S. and Pawar, P. J. (2017), An application of TOPSIS for selection of appropriate eGovernance practices to improve customer satisfaction, Journal of Project Management, 2(3), pp. 93-106.

Mirakian, E. A. and Hale, L. S. (2007), A Comparison of Online Instruction vs. Traditional Classroom Instruction in an Undergraduate Pharmacology Course, Proceedings of the 3rd Annual GRASP Symposium, Wichita State University, pp. 95-96.

Paul, J. and Jefferson, F. (2019), A Comparative Analysis of Student Performance in an Online vs. Face-toFace Environment Science Course From 2009 to 2016, Frontiers in Computer Science, 1:7, DOI: 10.3389/fcomp.2019.00007

Rao, R. V. (2007), Decision making in the manufacturing environment: using graph theory and fuzzy multiple attribute decision making methods, SpringerVerlag, London.

Sadiku, M. N. O., Adebo, P. O. and Musa, S. M. (2018), Online Teaching and Learning, International Journals of Advanced Research in Computer Science and Software Engineering, 8(2), 73-75.

Sangle, S. B., Nandurkar, K. N. and Pawar, P. J. (2020), Incorporating E-assessment tools in teaching for effective and authentic assessment, Journal of Engineering Education Transformations, 33, Special Issue, ICTIEE 2020, pp. 130-136. DOI:10.16920/jeet/2020/v33i0/150081

Shahabadkar, P., Joshi, A. and Nandurkar, K. (2019), Developing IT Enabled Mechanism for SWOC Analysis: A Case Study, Proceedings of the 2nd International Conference on Manufacturing Excellence, pp. 158-164. ISBN: 978-93-88441-69-8.

Singh, G. (2016), Challenges for Teachers in the Era of E-learning in India, Scholedge International Journal of Multidisciplinary \& Allied Studies, 3(2), pp. 14-18.

Vijaykumar, N., Gaitonde, V. N., Madhusudana, H. K., Lakkundi, A. R. and Praveenkumar (2016), Attainment of Higher Level of Blooms Taxonomy through Open Ended Activity in Metrology \& Quality Engineering lab, Journal of Engineering Education Transformations, Special Issue 2016, DOI: 10.16920/jeet/2016/v0i0/85516

Yoon, K. (1987) 'A Reconciliation Among Discrete Compromise Situations', Journal of Operational Research Society, 38(3), pp. 277-286. 